\title{
Improvement of a Real Gas-Sensor for the Origin of Methane Selectivity Degradation by $\mu$-XAFS Investigation
}

\author{
Takahiro Wada $\cdot$ Naoyoshi Murata $\cdot$ Takuya Suzuki $\cdot$ Hiromitsu Uehara $\cdot$ Hiroaki Nitani $\cdot$ \\ Yasuhiro Niwa • Motohiro Uo • Kiyotaka Asakura
}

Received: 16 October 2014 / Accepted: 1 February 2015/Published online: 17 February 2015

(C) The Author(s) 2015. This article is published with open access at Springerlink.com

\begin{abstract}
We have directly investigated the chemical state of the Pd species in a real $\mu$-gas sensor device by examining the $\mu$-fluorescence $\mathrm{X}$-ray absorption fine structure. The $\mu$-gas sensor device was heavily damaged by a heating process in which the temperature was ill-controlled, resulting in decrease of methane selectivity. We found that the PdO in the fresh $\mu$-gas sensor was reduced to Pd metal particles as the methane selectivity decreased. Based on the investigation results, we modified the device structure so as to heat up homogeneously. The lifetime of the sensor was then successfully increased by more than 5 years.
\end{abstract}

Keywords Micro gas sensor $\cdot$ Micro-XAFS $\cdot \mathrm{Pd} / \mathrm{Al}_{2} \mathrm{O}_{3} \cdot$ Deactivation

\section{Introduction}

Natural gas is now used for household energy resources because of its ease of use and environmental friendliness. The development of safety measures, such as a gas leakage sensor is in strong demand. $\mathrm{SnO}_{2}$ is a kind of sensor materials, its electric conductivity changes with the gas composition at high temperature [1]. However, the requirement of the AC power supply hinders the daily use of

T. Wada $(\bowtie) \cdot$ M. Uo

Graduate School of Medical and Dental Sciences, Tokyo

Medical and Dental University, Tokyo 113-8549, Japan

e-mail: wada.abm@tmd.ac.jp

N. Murata $\cdot$ T. Suzuki

Corporate R\&D Headquarters, Fuji Electric Co., Ltd.,

Tokyo 191-8502, Japan

H. Uehara $\cdot$ K. Asakura ( $\square)$

Catalysis Research Center, Hokkaido University,

Sapporo 001-0021, Japan

e-mail: askr@cat.hokudai.ac.jp

H. Nitani · Y. Niwa

Photon Factory, Institute of Materials Structure Science, KEK,

Tsukuba 305-0801, Japan the $\mathrm{SnO}_{2}$ gas sensor in the house because of the installation problem and the bad appearance.

Recently, Suzuki et al. have successfully developed a new $\mathrm{SnO}_{2}$ battery-driven sensor by a micro-electro-mechanical system (MEMS) method to achieve low power consumption [2,3]. The key factors are the promoting catalysts and pulse-heating system. Figure 1 shows a schematic drawing of the $\mu$-gas sensor chip involved. It is composed of a $\mathrm{Pd} / \mathrm{Al}_{2} \mathrm{O}_{3}$ catalyst overlayer, $\mathrm{Pt}-\mathrm{SnO}_{2}$ catalyst layer, $\mathrm{SnO}_{2}$ thin layer, electrode, and heater, which are sequentially deposited on a $\mathrm{Si}$ chip, giving the sensor high sensitivity and selectivity for methane. The $\mathrm{SnO}_{2}$ layer at the bottom was the heart of the sensor where the conductivity changes according to the concentration of the reductant gases. It was empowered by $\mathrm{Pt} / \mathrm{SnO}_{2}$ layer with its sensitivity. $\mathrm{Pd} / \mathrm{Al}_{2} \mathrm{O}_{3}$ increased the methane selectivity probably due to its high combustion activity of other reductant gases than methane [4]. A model sensor of a few square centimeter in area has been developed on a large $\mathrm{Si}$ substrate where the $\mathrm{SnO}_{2}$ thin layer, $\mathrm{Pt}-\mathrm{SnO}_{2}$, and $\mathrm{Pd} /$ $\mathrm{Al}_{2} \mathrm{O}_{3}$ layers were deposited. Murata et al. characterized the structure of this model system using X-ray absorption fine structure (XAFS) and X-ray photoelectron spectroscopy (XPS). They revealed that the high sensitivity was due to the $\mathrm{Pt}^{4+}$ located in the $\mathrm{SnO}_{2}$ lattice [5]. However, in 


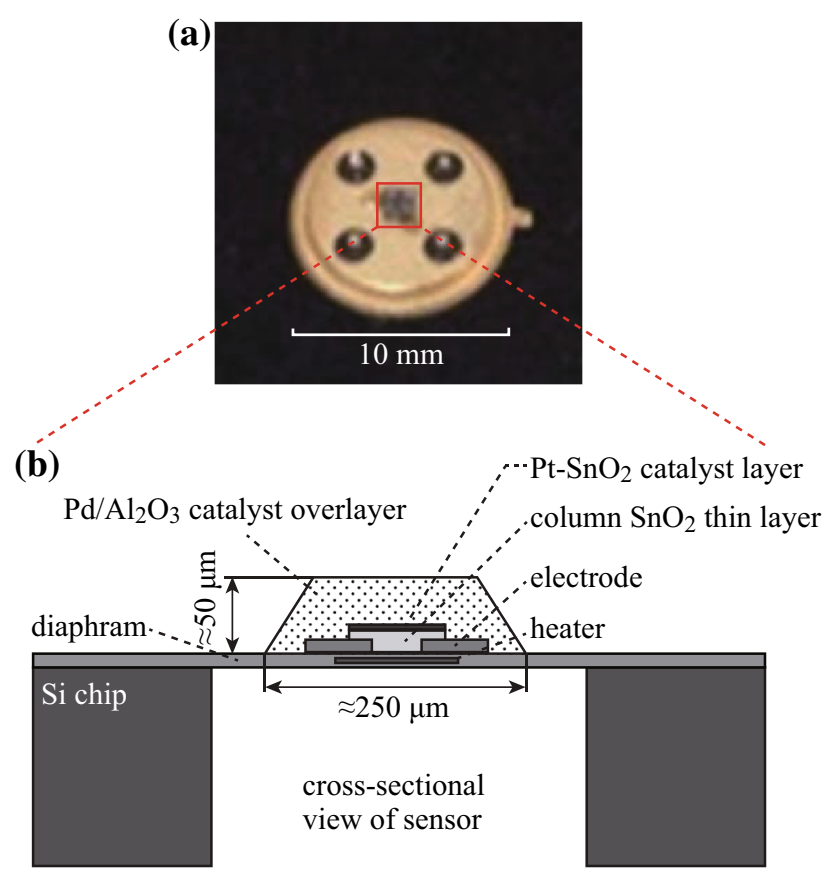

Fig. 1 a Photograph of $\mu$-gas sensor. b Diagram of $\mu$-gas sensor chip cross section

the real sensor device, the lifetime was not stable enough, especially in the selectivity for methane, although the sensitivity of the $\mathrm{SnO}_{2}$ thin layer was maintained. The selectivity instability was found to be related to the illcontrolled heating of the $\mu$-gas sensor system. Since $\mathrm{Pd} /$ $\mathrm{Al}_{2} \mathrm{O}_{3}$ is responsible for the selectivity and the damaging process can hardly be reproduced exactly in a model large sensor system, we directly investigated the structure of the $\mathrm{Pd} / \mathrm{Al}_{2} \mathrm{O}_{3}$ layer in a real, small $\mu$-gas sensor, the diameter of which was about $250 \mu \mathrm{m}$, before and after the damaging process. Therefore, the measurement of this sample requires $\mu \mathrm{m}$ order spatial-resolved XAFS, so called $\mu$-XAFS. We used a $\mu$-XAFS method to investigate the origin of the decrease in selectivity. We used a polycapillary lens to focus the $\mathrm{X}$-ray into a $\mu$-beam [6-9]. The $\mu$-X-ray size was smaller than the sensor's $\mathrm{Pd} / \mathrm{Al}_{2} \mathrm{O}_{3}$ area. We could monitor the structure change of the $\mu$-gas sensor. In this paper, we discuss the possible origin for the decreases in the methane selectivity of the $\mu$-gas sensor together with the role of the $\mathrm{Pd} / \mathrm{Al}_{2} \mathrm{O}_{3}$ layer and the importance of homogeneous heating in the gas sensor.

\section{Experimental}

\section{$2.1 \mu$-XAFS}

Pd K-edge $\mu$-XAFS experiments were performed at the NW-10A beamline at the Photon Factory (Institute for
Materials Structure Science, High Energy Accelerator Research Organization; KEK-IMSS-PF) using a Si (311) double crystal monochromator in a fluorescence mode [10]. The original beam size of this beamline was $1 \times 1 \mathrm{~mm}^{2}$.

A polycapillary lens is used in such microanalysis techniques as X-ray fluorescence analysis (XRF) [11-14], XAFS [15-19], and photoemission electron microscopy (PEEM) [20]. Some pioneers reported confocal measurement will give the $3 \mathrm{D}$ resolved point analysis using two capillaries or a combination of capillary and other x-ray optics [21-26]. The X-ray beam was focused by a polycapillary lens having a focal distance of $9.5 \mathrm{~mm}$ and transmission efficiency of about $8 \%$ at $25 \mathrm{keV}$ (XOS Inc., USA). The experimental setup is given in Fig. 2. The incident X-ray beam intensities were monitored by a $170 \mathrm{~mm}$-long ionization chamber. The X-ray fluorescence was detected by a 19-element Ge-SSD (Ortec, USA). The focal spot size was about $25 \mu \mathrm{m}$ in diameter (FWHM) as measured by knife-edge scans. XAFS spectra were analyzed using REX2000 software (Ver. 2.5, Rigaku, Japan) [27].

\section{$2.2 \mu$ Gas Sensor}

The $\mu$-gas sensors were prepared as described elsewhere [2, $3,5,28,29]$. Figure 1 shows the structure of the $\mu$-gas sensor. The $\mathrm{Pd} / \mathrm{Al}_{2} \mathrm{O}_{3}$ thickness was about $50 \mu \mathrm{m}$. We set the X-rays parallel to the sensor base, as shown in Fig. 2, where the maximum fluorescence X-ray intensity was obtained. The methane selectivity of the sensor was decreased when the sensor underwent ill-controlled temperature treatment where the heating temperature varied as $653 \pm 50 \mathrm{~K}$. When the temperature was well-controlled at
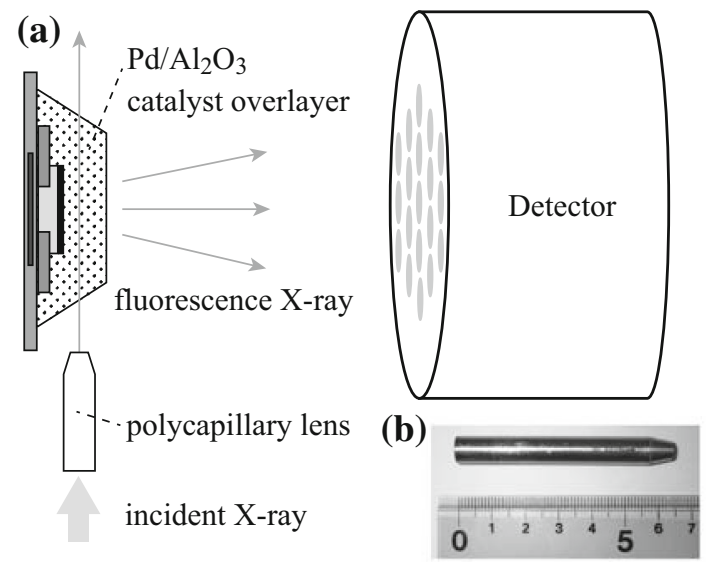

Fig. 2 a Alignments of $\mu$-beam and $\mu$-gas sensor. The sample surface was mounted roughly parallel to the X-ray incident direction and the detector surface. The cross section area of the X-ray is $25 \mu \mathrm{m}$ in FWHM diameter as measured by a knife-edge scan. b Photograph of polycapillary lens 
$703 \mathrm{~K}$, the decrease in the selectivity was not observed, as shown in Fig. 3. The sample was treated to obtain a damaged sample for the acceleration aging test, where the $\mu$-gas sensors were driven in a flow of $500 \mathrm{ppm} \mathrm{H}_{2}$ (a model reductant gas), and $99 \%$ relative humidity (RH). Selectivity $(\mathrm{Sel})$ was defined as follows:

$\mathrm{Sel}=R_{\text {hydrogen }} / R_{\text {methane }}$

where $R_{\text {hydrogen }}$ and $R_{\text {methane }}$ are the resistance in flow of $1000 \mathrm{ppm} \mathrm{H}_{2}$ and $1000 \mathrm{ppm} \mathrm{CH}_{4}$ at $20{ }^{\circ} \mathrm{C}$ and $65 \% \mathrm{RH}$. Four typical examples $\mathrm{Sel}=5.2 \quad$ (Fresh), $\mathrm{Sel}=3.7$ (Sel3.7), $\mathrm{Sel}=1.8$ (Sel1.8), and $\mathrm{Sel}=0.9$ (Sel0.9) were measured.

\section{Results and Discussion}

Figure 4 shows the Pd K-edge XANES (Fig. 4a) and EXAFS (Fig. 4b) for fresh and treated samples. We could obtain enough data for analysis as shown in Fig. 5, even if the sample thickness was only $50 \mu \mathrm{m}$ using a polycapillary tube.

The XANES spectrum in the fresh sample was much more similar to those of $\mathrm{PdO}$ and $\mathrm{Pd}(\mathrm{OH})_{2}$ rather than $\mathrm{Pd}$ foil. When the methane selectivity was decreased, the XANES changed a little. The first edge peak $(24,350 \mathrm{eV})$ decreased with the increase in the higher energy side $(24,360 \mathrm{eV})$ as the methane selectivity decreased. EXAFS Fourier transforms provided more definite structural information. In the Fourier transform of the fresh sample, $\mathrm{Pd}-\mathrm{O}$ was found at $0.16 \mathrm{~nm}$ together with $\mathrm{Pd}-\mathrm{Pd}$ at about $0.3 \mathrm{~nm}$, indicating the formation of $\mathrm{PdO}$, not $\mathrm{Pd}(\mathrm{OH})_{2}$. As the methane selectivity decreased, we found a new, emerging peak at $0.25 \mathrm{~nm}$ in the Fourier transform. This new peak could be assigned to the Pd-Pd bond in the Pd metal. The height of this peak increased with the decrease

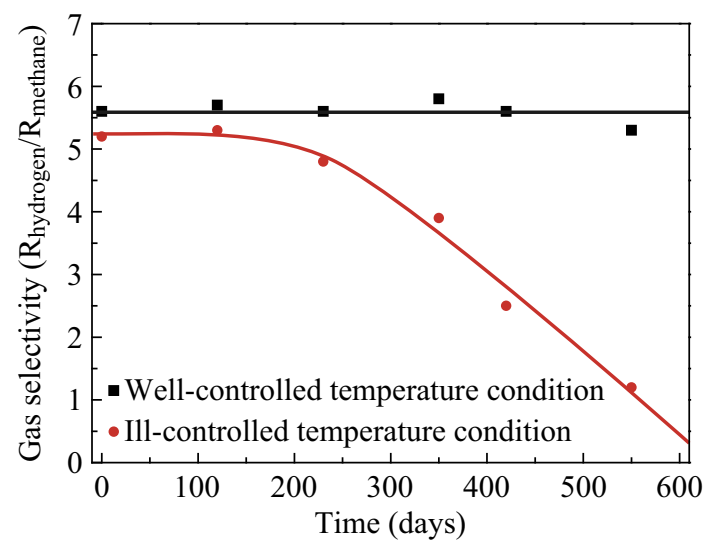

Fig. 3 Test results for accelerated aging of the samples subjected to well-controlled (square) and the ill-controlled (circle) temperature conditions

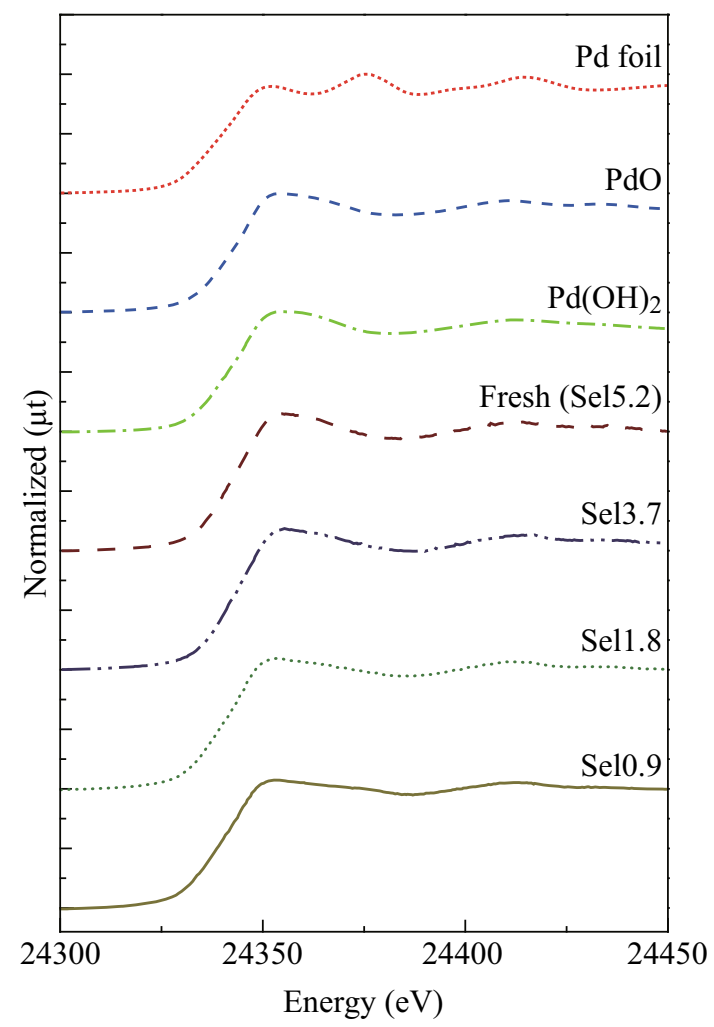

(a)

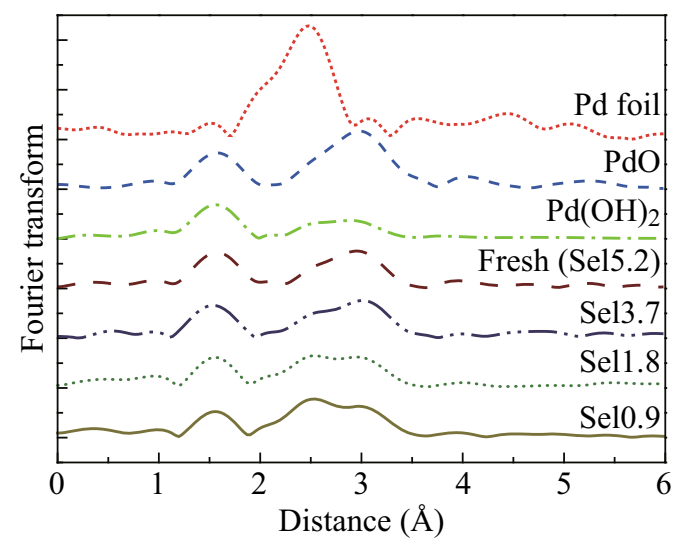

(b)

Fig. 4 a Pd K-edge XANES spectrum. b Pd K-edge FT-EXAFS

in methane selectivity. Curve fitting results indicated the presence of $\mathrm{Pd}$ at $0.273 \pm 0.004 \mathrm{~nm}$ with a coordination number of $2.8 \pm 0.6$ in Sel0.9. In Sel3.7 and Sel1.8, we found the coordination number of the Pd-Pd bond in $\mathrm{Pd}$ metal to be $0.9 \pm 0.4$ and $2.4 \pm 1.0$, respectively.

The decrease in the methane selectivity seemed to be strongly correlated with the formation of Pd metal particles. We assumed that the change of XANES was due to the increase in Pd metal concentration in the composition. We carried out a linear combination analysis using XANES spectra of Pd foil and PdO. Figure 6 shows the fitting results 


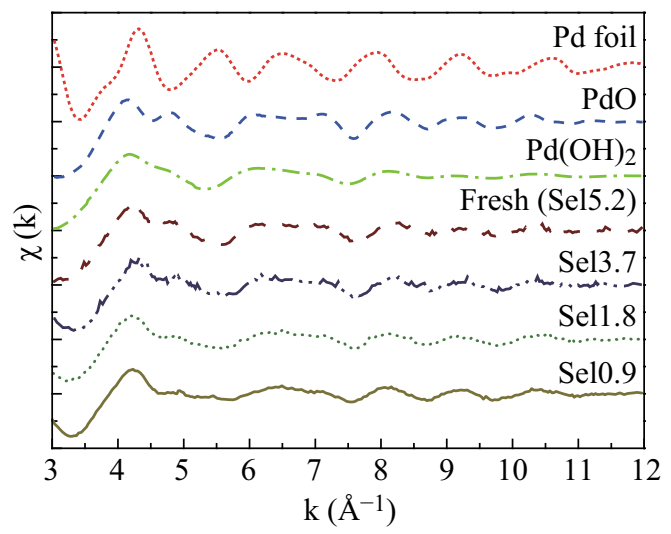

Fig. 5 Pd K-edge EXAFS spectrum of real sensor head measured by polycapillary

for the Sel0.9 sample. The data were well reproduced using spectra of metallic Pd (38 at.\%) and PdO (62 at.\%).

The decrease in the selectivity was negatively proportional to the Pd metal content, as shown in Fig. 7. Errors of Pd metal content were estimated using the Hamilton ratio method [30] at a confidence level of $95 \%$. Therefore, the selectivity decrease occurred due to the formation of $\mathrm{Pd}$ particles.

Previous research has shown that the function of the $\mathrm{Pd} /$ $\mathrm{Al}_{2} \mathrm{O}_{3}$ catalyst is to improve the selectivity for methane [4]. Methane is inert compared to the other gases that are present. The $\mathrm{PdO}$ in the $\mathrm{Pd} / \mathrm{Al}_{2} \mathrm{O}_{3}$ layer can burn up the other gases (hydrogen, alcohol, carbon monoxide, etc.) completely, but not the methane that reaches the sensor part $\left(\mathrm{SnO}_{2}\right.$ thin layer). The formation of $\mathrm{Pd}$ changes the activity and selectivity of the $\mathrm{Pd} / \mathrm{Al}_{2} \mathrm{O}_{3}$ overlayer. Consequently, the selectivity decreases. $\mathrm{Pd}$ and $\mathrm{PdO}$ have different activation behaviors for hydrogen and other gases [31]. The PdO is necessary for the selective combustion and increases the selectivity.

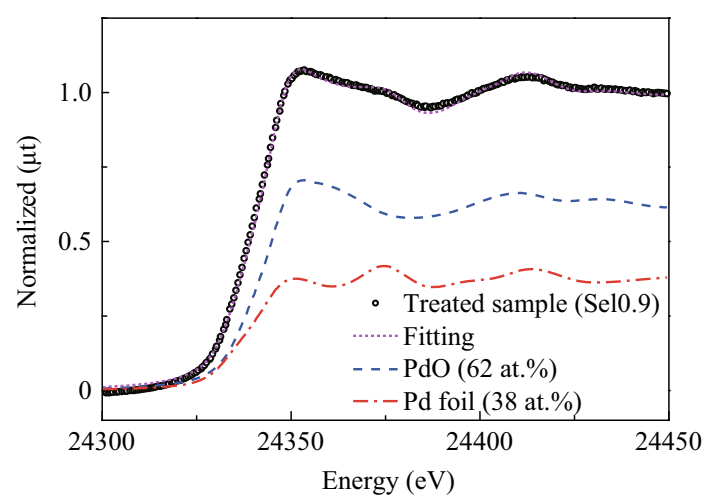

Fig. 6 Linear combination fitting results using XANES spectra of Pd foil and PdO. The XANES spectra were of a treated sample (Sel0.9) (open circle). a Fitting results combined b $\mathrm{PdO}$ (62 at.\%) and $\mathbf{c} \mathrm{Pd}$ foil (38 at.\%)

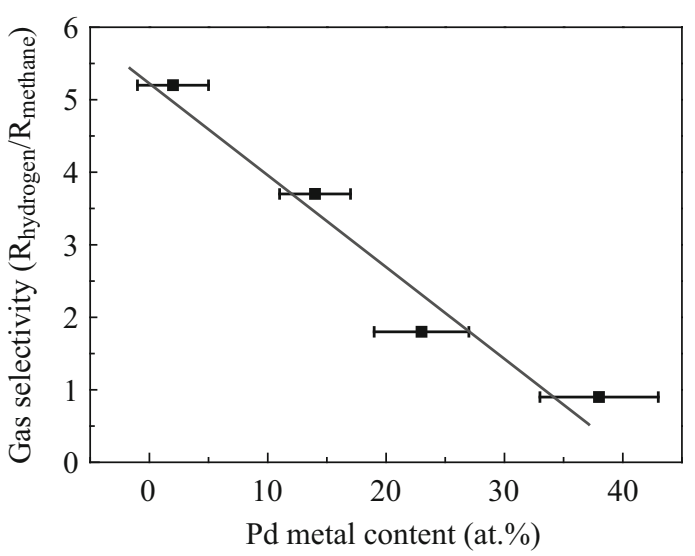

Fig. 7 Relation between the methane selectivity and PdO content

Under ill-controlled temperature conditions, the Pd was not always heated up to $703 \mathrm{~K}$. In the model system, we found the $\mathrm{PdO}$ was reduced at intermediate temperatures $(500-600 \mathrm{~K})$ in the presence of $\mathrm{H}_{2}$ and reoxidation of $\mathrm{Pd}$ metal occurred at higher temperatures [31]. Therefore, insufficient heating may sometimes create Pd particles, which may aggregate. Once the Pd is aggregated into large metal particles, high-temperature heat treatment cannot redisperse the Pd particles to the $\mathrm{PdO}$ again, even at $703 \mathrm{~K}$. In the sample that was subjected to ill-controlled temperature conditions, the aggregation to form large Pd particles might occur slowly but steadily, causing the sensor to gradually lose its selectivity. Moisture also accelerates the aggregation process [4]. Under the influence of moisture, the surface of $\mathrm{PdO}$ might consist of $\mathrm{Pd}(\mathrm{OH})_{2}$, which should show high mobility and thus accelerate the aggregation of large Pd particles $[32,33]$. In the dry gas, the acceleration rate of the decreasing selectivity was low. The heating treatment at $703 \mathrm{~K}$ also helps the removal of surface $\mathrm{Pd}(\mathrm{OH})_{2}$ species. We conclude the $\mathrm{PdO}$ is the key factor in keeping the high selectivity for methane. The $\mathrm{Pd} / \mathrm{Al}_{2} \mathrm{O}_{3}$ layer of micro gas sensors structure was modified to increase the heat retention capability and the contact area to the heater and to decrease the thermal capacity. As results, it allowed that the temperature was kept around $703 \mathrm{~K}$ homogeneously without increasing power consumption and $\mathrm{PdO}$ structure can be maintained. Based on the knowledge obtained here, the battery-driven $\mu$-sensor has been realized to attain the enough lifetime more than 5 years with the sensor structure to heat the sensor homogeneously.

\section{Conclusion}

In this work, an X-ray $\mu$-beam made by a polycapillary was used to measure the $\mu$-XAFS of a model $\mu$-gas sensor. These results suggest that the ill-controlled heating of the $\mu$-gas 
sensor system caused the reduction of PdO to Pd metal particles at medium temperature. Since the Pd nanoparticle was active for the oxidation reaction of methane, the methane selectivity decreased. However, at a higher temperature than $703 \mathrm{~K}$, the Pd was kept in PdO structure even in the presence of reductant gas $\left(\mathrm{H}_{2}\right)$, indicating that the homogeneous heating of the sensor is essential to keep the PdO structure. Based on this result, the $\mu$-gas sensor structure has been modified to keep the sensor device at the high temperature homogeneously, and the sensor lifetime has successfully been increased by more than 5 years. The $\mu$-XAFS is a powerful analytical tool that gives important information in understanding the mechanism of real devices at the atomic level.

Acknowledgments All XAFS measurements were conducted at the Photon Factory, High Energy Accelerator Organization under Proposal Number 2012G680. The investigation was performed under the support of the New Energy and Industrial Technology Development Organization (NEDO).

Open Access This article is distributed under the terms of the Creative Commons Attribution License which permits any use, distribution, and reproduction in any medium, provided the original author(s) and the source are credited.

\section{References}

1. C.X. Wang, L.W. Yin, L.Y. Zhang, D. Xiang, R. Gao, Metal oxide gas sensors: sensitivity and influencing factors. Sensors 10(3), 2088-2106 (2010). doi:10.3390/s100302088

2. T. Suzuki, K. Kunihara, M. Kobayashi, S. Tabata, K. Higaki, H. Ohnishi, A micromachined gas sensor based on a catalytic thick film $/ \mathrm{SnO}_{2}$ thin film bilayer and thin film heater-Part 1: $\mathrm{CH}_{4}$ sensing. Sens. Actuators B Chem. 109(2), 185-189 (2005). doi:10.1016/j.snb.2005.05.013

3. S. Tabata, K. Higaki, H. Ohnishi, T. Suzuki, K. Kunihara, M. Kobayashi, A micromachined gas sensor based on a catalytic thick film $/ \mathrm{SnO}_{2}$ thin film bilayer and a thin film heater-Part 2: CO sensing. Sens. Actuators B Chem. 109(2), 190-193 (2005). doi:10.1016/j.snb.2005.05.012

4. J.C. Kim, H.K. Jun, J.-S. Huh, D.D. Lee, Tin oxide-based methane gas sensor promoted by alumina-supported Pd catalyst. Sens. Actuators B Chem. 45(3), 271-277 (1997). doi:10.1016/ S0925-4005(97)00325-0

5. N. Murata, T. Suzuki, M. Kobayashi, F. Togoh, K. Asakura, Characterization of Pt-doped $\mathrm{SnO}_{2}$ catalyst for a high-performance micro gas sensor. Phys. Chem. Chem. Phys. 15(41), 17938-17946 (2013). doi:10.1039/c3cp52490f

6. M.A. Kumakhov, Channeling of photons and new X-ray optics. Nucl. Instrum. Methods Phys. Res. B 48(1-4), 283-286 (1990). doi:10.1016/0168-583X(90)90123-C

7. M.A. Kumakhov, F.F. Komarov, Multiple reflection from surface X-ray optics. Phys. Rep. 191(5), 289-350 (1990). doi:10.1016/ 0370-1573(90)90135-O

8. P.J. Schields, D.M. Gibson, W.M. Gibson, N. Gao, H.P. Huang, I.Y. Ponomarev, Overview of polycapillary X-ray optics. Powder Diffr. 17(2), 70-80 (2002). doi:10.1154/1.1482080

9. N. Gao, K. Janssens, in X-Ray spectrometry: recent technological advances: polycapillary X-ray optics, ed. by K. Tsuji, J. Injuk, R. Van Grieken (Wiley, Chichester, 2005), pp. 89-110
10. M. Nomura, Y. Koike, M. Sato, A. Koyama, Y. Inada, K. Asakura, A new XAFS beamline NW10A at the photon factory. AIP Conf. Proc. 882(1), 896-898 (2007). doi:10.1063/1.2644697

11. N. Gao, I.Y. Ponomarev, Q.F. Xiao, W.M. Gibson, D.A. Carpenter, Monolithic polycapillary focusing optics and their applications in microbeam X-ray fluorescence. Appl. Phys. Lett. 69(11), 1529-1531 (1996). doi:10.1063/1.117994

12. A. Bjeoumikhov, N. Langhoff, S. Bjeoumikhova, R. Wedell, Capillary optics for micro X-ray fluorescence analysis. Rev. Sci. Instrum. 76(6), 063115 (2005). doi:10.1063/1.1938847

13. L. Cheng, X. Ding, Z. Liu, Q. Pan, X. Chu, Development of a micro-X-ray fluorescence system based on polycapillary X-ray optics for non-destructive analysis of archaeological objects. Spectrochim. Acta Part B 62(8), 817-823 (2007). doi:10.1016/j. sab.2007.06.010

14. T. Sugiyama, M. Uo, T. Wada, D. Omagari, K. Komiyama, T. Noguchi, Y. Jinbu, M. Kusama, Estimation of trace metal elements in oral mucosa specimens by using SR-XRF, PIXE, and XAFS. Biometals 28(1), 11-20 (2015). doi:10.1007/s10534-0149796-6

15. L. Vincze, F. Wei, K. Proost, B. Vekemans, K. Janssens, Y. He, Y. Yan, G. Falkenberg, Suitability of polycapillary optics for focusing of monochromatic synchrotron radiation as used in trace level micro-XANES measurements. J. Anal. At. Spectrom. 17(3), 177-182 (2002). doi:10.1039/b110210a

16. G. Silversmit, B. Vekemans, S. Nikitenko, W. Bras, V. Czhech, G. Zaray, I. Szaloki, L. Vincze, Polycapillary-optics-based microXANES and micro-EXAFS at a third-generation bending-magnet beamline. J. Synchrotron Radiat. 16, 237-246 (2009). doi:10. 1107/S0909049508043306

17. T. Sun, Y. Xie, Z. Liu, T. Liu, T. Hu, X. Ding, Application of a combined system of polycapillary X-ray lens and toroidal mirror in micro-X-ray-absorption fine-structure facility. J. Appl. Phys. 99(9), 094907-1-094907-4 (2006). doi:10.1063/1. 2193050

18. T. Sun, Z. Liu, X. Ding, Characterization of a polycapillary focusing X-ray lens for application in spatially resolved EXAFS experiments. Chem. Phys. Lett. 439(4-6), 412-414 (2007). doi:10.1016/j.cplett.2007.03.105

19. M. Uo, K. Asakura, K. Watanabe, F. Watari, XAFS analysis of the bronchoalveolar lavage fluid of a tungsten carbide pneumoconiosis patient. Chem. Lett. 39(8), 852-853 (2010). doi:10.1246/ cl.2010.852

20. N. Hirao, Y. Baba, T. Sekiguchi, Quick observation of photoelectron emission microscopy with focused soft X-rays using poly-capillary lens (Proceedings of the 5th international symposium on practical surface analysis, PSA-10 and 7th Korea-Japan international symposium on surface analysis). J. Surf. Anal. 17(3), 227-231 (2011)

21. W.M. Gibson, M.A. Kumakhov, Applications of X-ray and neutron capillary optics. X-ray detector physics and applications. Proc. SPIE 1736, 172-189 (1993). doi:10.1117/12.140473

22. X. Ding, N. Gao, G.J. Havrilla, Monolithic polycapillary X-ray optics engineered to meet a wide range of applications. Proc. SPIE 4144, 174-182 (2000). doi:10.1117/12.405891

23. K. Tsuji, K. Nakano, X. Ding, Development of confocal micro $\mathrm{X}$-ray fluorescence instrument using two X-ray beams. Spectrochim. Acta Part B 62(6-7), 549 (2007). doi:10.1016/j.sab. 2007.02.014

24. T. Sun, X. Ding, Z. Liu, G. Zhu, Y. Li, X. Wei, D. Chen, Q. Xu, Q. Liu, Y. Huang, X. Lin, H. Sun, Characterization of a confocal three-dimensional micro $\mathrm{X}$-ray fluorescence facility based on polycapillary X-ray optics and Kirkpatrick-Baez mirrors. Spectrochim. Acta Part B 63(1), 76-80 (2008). doi:10.1016/j.sab. 2007.11.003 
25. T.X. Sun, H.H. Liu, Z.G. Liu, S. Peng, Y.Z. Ma, W.Y. Sun, P. Luo, X.L. Ding, Application of confocal technology based on polycapillary X-ray optics in three-dimensional diffraction scanning analysis. Nucl. Instrum. Methods Phys. Res. B 323, 25-29 (2014). doi:10.1016/j.nimb.2014.01.013

26. S. Peng, Z.G. Liu, T.X. Sun, Y.Z. Ma, X.L. Ding, Spatially resolved in situ measurements of the ion distribution near the surface of electrode in a steady-state diffusion in an electrolytic tank with confocal micro X-ray fluorescence. Analy. Chem. 86(1), 362-366 (2014). doi:10.1021/ac403188k

27. T. Taguchi, REX2000 Version 2.5: improved DATA handling and enhanced user-interface. AIP Conf. Proc. 882(1), 162-164 (2007). doi:10.1063/1.2644462

28. M. Kobayashi, M. Yoshida, T. Suzuki, K. Kunihara, S. Tabata, K. Higaki, H. Ohnishi, T. Hashimoto, Jpn. Patent JP4376093, 2009

29. T. Suzuki, K. Onodera, F. Inoue, K. Tsuda, Jpn. Patent JP3812215, 2006
30. W.C. Hamilton, Significance tests on the crystallographic R factor. Acta Crystallogr. 18(3), 502-510 (1965). doi:10.1107/ S0365110X65001081

31. M.G. Jones, T.G. Nevell, R.J. Ewen, C.L. Honeybourne, Oxidation-state of the surface of palladium in the catalytic combustion of hydrogen. Appl. Catal. 70(1), 277-286 (1991). doi:10.1016/ S0166-9834(00)84170-6

32. J.M. Jehng, G. Deo, B.M. Weckhuysen, I.E. Wachs, Effect of water vapor on the molecular structures of supported vanadium oxide catalysts at elevated temperatures. J. Mol. Catal. A: Chem. 110(1), 41-54 (1996). doi:10.1016/1381-1169(96)00061-1

33. K. Okumura, R. Yoshimoto, T. Uruga, H. Tanida, K. Kato, S. Yokota, M. Niwa, Energy-dispersive XAFS studies on the spontaneous dispersion of $\mathrm{PdO}$ and the formation of stable $\mathrm{Pd}$ clusters in zeolites. J. Phys. Chem. B 108(20), 6250-6255 (2004). doi:10.1021/jp037187b 